Document downloaded from:

http://hdl.handle.net/10251/171316

This paper must be cited as:

Broatch, A.; Olmeda, P.; Xandra-Marcelle, M.; Escalona-Cornejo, JE. (2021). Conjugate heat transfer study of the impact of "thermo-swing" coatings on internal combustion engines heat losses. International Journal of Engine Research. 22(9):2958-2967. https://doi.org/10.1177/1468087420960617

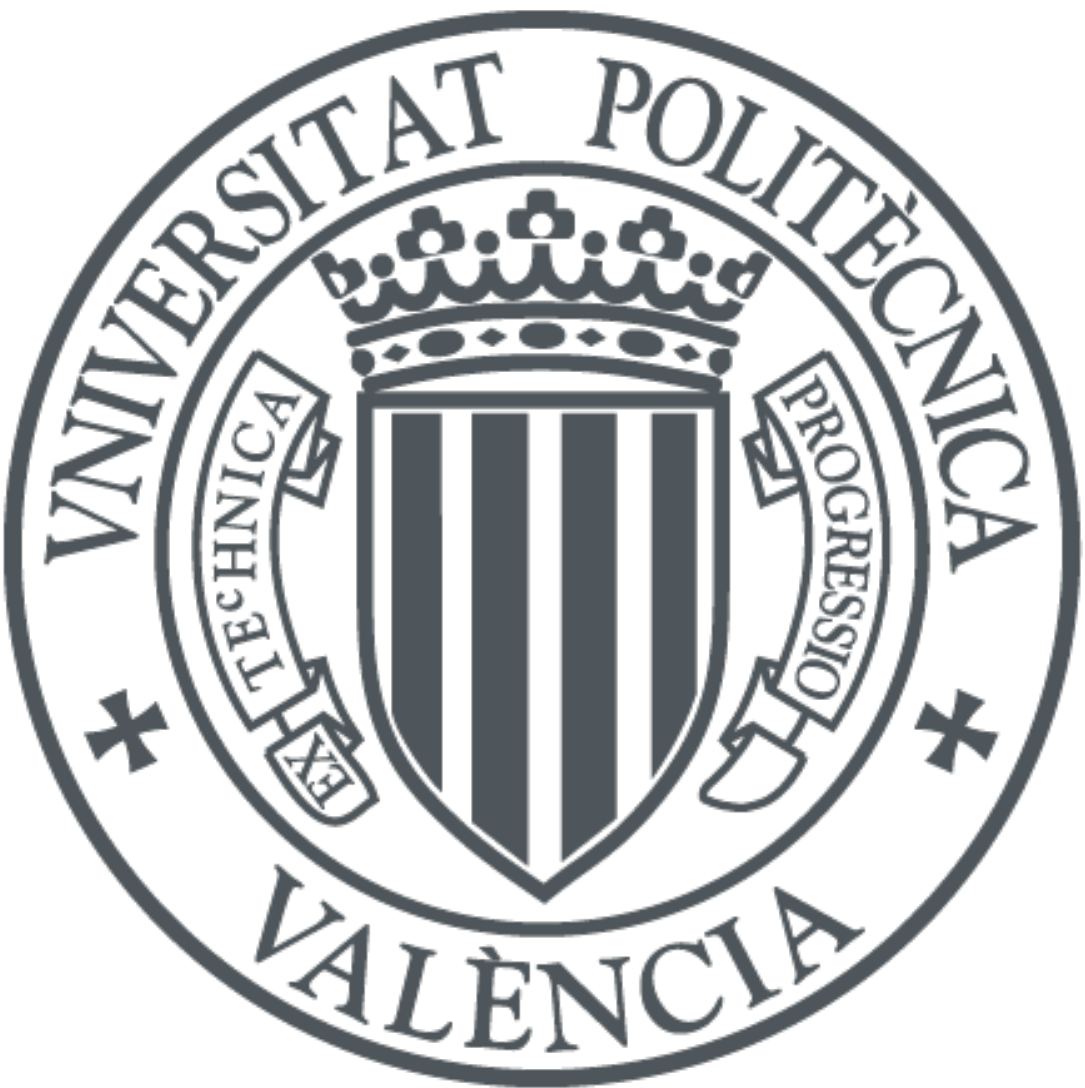

The final publication is available at

https://doi.org/10.1177/1468087420960617

Copyright SAGE Publications

Additional Information 


\title{
Conjugate Heat Transfer study of the impact of "thermo-swing" coatings on Internal Combustion Engines heat losses
}

\author{
A. Broatch, P. Olmeda, X. Margot*, J. Escalona \\ CMT - Motores Térmicos, Universitat Politècnica de València, Camino de Vera, 46022 Valencia, Spain
}

\begin{abstract}
To comply with the very strict emissions regulation the automotive industry is succeeding in developing ever more efficient engines, and there is scope for more improvements. In this regard, some investigations have suggested that insulating the combustion chamber walls of an internal combustion engine (ICE) yield low thermal losses. Most of the literature available on this topic presents simplified models that do not allow studying in detail the coating impact on engine efficiency. A more precise approach that consists in the combination of Computational Fluid Dynamics (CFD) and Conjugate Heat Transfer (CHT) simulations is used in this paper to predict the heat losses through the combustion chamber walls of a spark ignition (SI) engine. Two configurations are considered for the single cylinder engine: the metallic case and the same engine with coated piston and cylinder head. The insulation material has a low thermal conductivity $(k<1.0 \mathrm{~W} /(\mathrm{mK}))$. The numerical results are validated by comparison with the results of a $1 \mathrm{D}$ heat transfer model and with experimental data for a medium load operation point (3000 rpm -7 bar IMEP). The solutions obtained are analyzed in detail in terms of wall temperature distribution and heat transfer. The impact of the coating on the engine efficiency is thus assessed. The CFD-CHT calculations yields very good results in terms of heat transfer prediction during the whole engine cycle.
\end{abstract}

Keywords: Conjugate Heat Transfer, Insulation coatings, Spark Ignition Engine, Combustion, CFD

\section{Introduction}

Over the last decades engine manufacturers have focused their efforts on developing new technologies resulting in more efficient and eco-friendly powertrains. These developments concern mainly the SI engines, as these are seen as having more improvement potential in terms of emissions, and also because they better fit new hybrid technologies. The main goal is to achieve an engine with lower emissions and higher efficiency [1+3]. Among the solutions that are being explored to improve thermal efficiency, one is the development of innovative insulating materials to coat some engine parts [4] 6 , such as the combustion chamber walls and the exhaust pipes manifold. However, the real global impact of coating these surfaces on the final engine performance is not clear. Hence, numerical and experimental studies need to be carried out before any commercial release.

Early researches about applying thermal barrier coatings in internal combustion engines (ICE) were carried out in the 1980s [7 9] targeting heat losses reduction. The approach consisted in using a material with low thermal conductivity and high thermal conductance to coat parts

*Corresponding author. Tel.: +34 963877650 , Email address: abroatch@mot.upv.es (A. Broatch), pabolgon@mot.upv.es (P. Olmeda), xmargot@mot.upv.es (X. Margot), joescor2@mot.upv.es (J. Escalona) of the combustion chamber in order to decrease the thermal gradient between the gas and the solid surfaces. The thermal efficiency of the engine could thus be improved. However, further studies showed the drawbacks of this concept on engine performance, such as the deterioration of the volumetric efficiency 10, 11. Also, the resulting higher temperatures of the coated chamber walls could favor knock occurrence in SI engines [12.

On the other hand, some investigations have stated that the use of coatings with low thermal conductivity and low thermal capacity may reduce the heat losses through the combustion chamber walls without affecting its volumetric efficiency [13]. With these materials the wall temperature follows the gas transient temperature evolution during the engine cycle [14, 15. Lower temperatures on the surfaces during intake are achieved [12, 16]. Toyota has been pioneer in introducing this 'Thermo-Swing Wall Insulation' (TSWIN) concept [17-19] in a turbocharged Diesel engine. They applied a novel advanced insulation material of low thermal conductivity, named SIRPA, on the lips of the piston and claimed a substantial gain in engine efficiency. The term "thermo-swing" was used to describe the fact that the temperature evolution of the insulated surface would follow the instantaneous gas temperature changes, thus reducing 
heat transfer through the combustion chamber walls. Since then, several other studies have been conducted to determine the impact of insulating the combustion chamber walls of an ICE [20, 21.

Developing new coating materials for ICEs is quite challenging as they have to combine optimal insulating properties with resistance and adherence properties to endure the engine operating conditions. Advanced test benches and numerical simulations are needed in order to determine the effectiveness of the coatings. From the experimental point of view, some R\&D studies have been carried out using optical techniques [19] to measure the temperature on the coated surfaces. However, there are many uncertainties linked to these measurements, highlighted by many other works available in the literature [11, 13, 22, 24, In this sense, the numerical simulations play an important role, since they may provide more detailed information at a much lesser cost.

In the last decades computational tools have become essential in the design and improvement of automotive powertrains. Among other things, Computational Fluid Dynamics (CFD) and Conjugate Heat Transfer (CHT) simulations are used to give insight into the physical processes that take place in an ICE, such as the combustion and the heat transfer through the walls, and to complement experimental measurements. There is indeed a diversity of papers available in the literature concerning these topics [11, 25 32].

There are however few numerical studies about the use of new insulation materials in ICEs. 0D-1D models can be used to define the optimal properties for the insulation coatings and study their impact on engine performance. CFD simulations have been performed by [1] to evaluate the effect on the combustion process of coating the piston and cylinder head of an SI engine. In this case the instantaneous temperature evolution of the coated surfaces was imposed as boundary condition without considering the heat transfer through the solid walls.

These works cannot provide detailed information about the temperature distribution on the insulated surfaces, so that maximum temperature hot spots cannot be identified for instance. Yet, identifying these is interesting to ensure material resistance. In addition, it is also important to calculate the heat transfer through the insulated surfaces in order to minimize the heat losses through the walls of the combustion chamber. This can only be done by a combined CFD-CHT modeling approach, which allows solving simultaneously in a coupled simulation the processes in the fluid domain of the combustion chamber and the heat transfer through the solid domain of the engine components. It therefore represents a useful means of studying the impact on engine performance of applying advanced insulation coatings on ICE combustion chamber walls.

The main objective of this work is two-fold. On the one hand, validate the use of a CFD-CHT approach to calculate accurately the instantaneous heat transfer through the combustion chamber walls during the whole engine cycle.
On the other hand, assess the impact of a new generation insulation material on engine heat losses for a medium load operation point. For this study, two configurations of a single cylinder engine SI engine have been considered, the metallic reference case and the same engine with coated piston and cylinder head.

The methodology, validation and results of this research are presented in the following sections of this paper. In section 2, all the details about the methodology for the CHT calculations are described. Section 3 presents the numerical set-up for the CHT model. In section 4 , the validation of the approach is presented with the analysis and discussion of the results. Finally, section 5 summarizes the conclusions about the suitability of the CHT approach to study the heat transfer in coated ICEs.

\section{Methodology}

The methodology followed for the CFD-CHT validation and simulations is summarized in Fig. 1. It can be divided in two main steps described below:

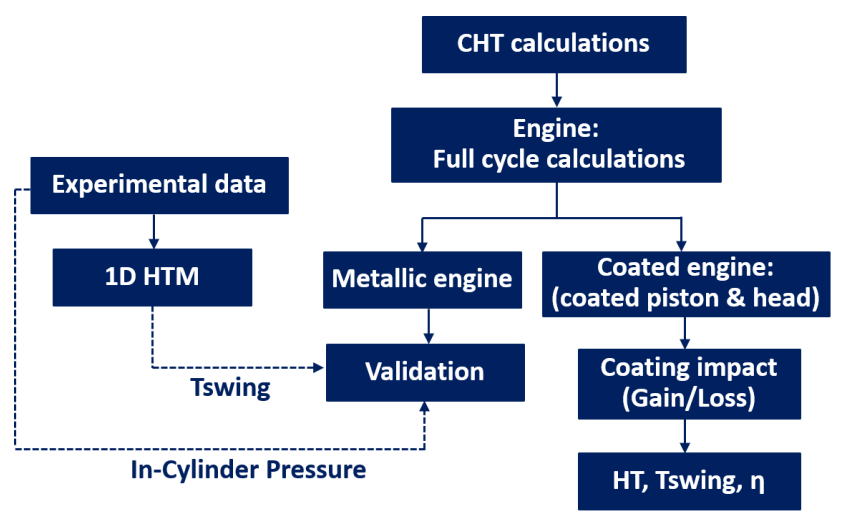

Figure 1: Methodology for CHT calculations.

\subsection{CFD-CHT validation with metallic engine}

For the full engine cycle simulations the whole gas exchange process (GEP), starting from exhaust valve opening (EVO) is also simulated together with the closed cycle. The piston and the cylinder head geometries are also included in the meshing, since CHT will be applied to these two solid parts. The calculations were performed for a medium load operation point (3000 rpm, 7 bar) of a single cylinder engine described in section 3.1 .

In order to validate the CHT results, the obtained mean temperature levels and swing on the piston wall are compared with the results of the 1D simulation performed with a 1D lumped model [11, 33. In addition, the fluid domain is validated by comparison of the experimental and simulated in-cylinder pressure traces [34, 35. 


\subsection{CFD-CHT for coated engine}

Following the same approach as described above, CFDCHT calculations are carried out with coated piston and cylinder head. The details of the coating material such as thickness, thermal conductivity and heat capacitance are specified in Table 1. It is one of the materials developed for the European project EAGLE (G.A.No. 724084) 36]. Finally, the results obtained with the coated engine are compared with those of the base aluminium engine in order to quantify the impact of the thermal insulation material.

Table 1: Coating insulation material properties

\begin{tabular}{lcc}
\hline & Piston & Cyl. Head \\
\hline Conductivity $[\mathrm{W} / \mathrm{mK}]$ & 0.85 & 0.85 \\
Heat capacitance $\left[k J / \mathrm{m}^{3} \mathrm{~K}\right]$ & 2600 & 2600 \\
Thickness $[\mu \mathrm{m}]$ & 160 & 140 \\
\hline
\end{tabular}

\section{Numerical setup}

\subsection{Geometry and engine specifications}

The computational domain for the calculations includes both the fluid and solid zones. The fluid region includes the single cylinder geometry, as well as the intake and exhaust ports, while the solid region is formed by the piston and cylinder head. In the case of the coated configuration the layer of insulating material is integrated in the solid on the gas exposed surfaces of the piston and cylinder head, so that the engine compression ratio remains unchanged. The engine geometry was provided by IFP Energies Nouvelles (IFPEN) and its main non-confidential characteristics are presented in Table 2 together with the operation condition used for the simulations.

Table 2: Engine specifications

\begin{tabular}{lc}
\hline Engine type & 4-stroke spark ignited \\
\hline IMEP [bar] & 7 \\
Engine speed [rpm] & 3000 \\
Bore - Stroke [mm] & $75-93$ \\
Compression ratio & $14: 1$ \\
Ignition timing [cad aTDC] & -27 \\
Number of valves [-] & 2 intake and 2 exhaust \\
\hline
\end{tabular}

\subsection{Mesh and model set-up}

The commercial CFD code CONVERGE v2.3 [37] based on the finite-volume method has been used for the CHT simulations presented in this paper. Based on previous mesh independence studies, the mesh for the engine is hexahedral with a base grid size of $2 \mathrm{~mm}$ and has been generated at run-time by a cut-cell Cartesian method. Furthermore, the grid size is reduced close to the combustion chamber ports and valves and at the fluid/solid interfaces of the piston and cylinder head to ensure good resolution of the boundary layer. The region near the spark plug was also refined at the start of the ignition to adequately model the combustion process [38, 39]. Furthermore, an adaptive mesh refinement algorithm (AMR) available in the code was used to refine the combustion chamber base grid in regions with significant gradients of temperature and velocity.

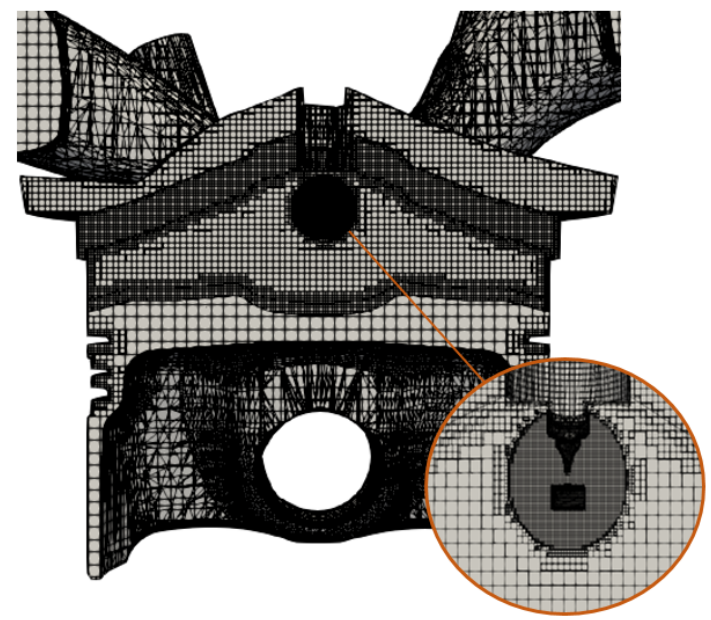

Figure 2: Mesh of the computational domain at -27 aTDC.

The meshed computational domain for the calculations is shown in Fig. 2, including both the fluid and solid domains.

\subsection{Models and boundary conditions}

To model the combustion process, the SAGE detailed chemistry solver, which uses local conditions to calculate reaction rates based on the principles of chemical kinetics [40] was employed. The RNG (re-normalization group) k- $\epsilon$ [41] was chosen to model turbulence, in combination with the O'Rourke and Amsden for heat transfer to the wall 42, 43. Compressible flow properties were defined with the Redlich-Kwong state equation [44. The pressure-velocity coupling in CONVERGE is achieved using a modified Pressure Implicit with Splitting of Operators (PISO) algorithm 45].

Considering that it takes much longer to converge the solid region than the fluid region, the super-cycling approach of CONVERGE has been used to solve the conjugate heat transfer problem [37], whereby the fluid and the solid are coupled in a fully transient calculation. The heat transfer coefficient (HTC) and the near wall temperature at the fluid/solid interface cells are stored in stages at defined time-step intervals. The super-cycling speeds up the convergence of the solid by reducing the number of cycles needed. Indeed, the fluid solver is frozen at the super-cycling time step intervals, while the solid heat conduction problem is converged to steady state using time averaged boundary conditions from the stored fluid temperatures and HTC. 
The coupling of fluid and solid is then resumed and the process repeated until the solid temperature has converged. For the prediction of the the wall temperature evolution on the solid surfaces a supercycling time step interval of $720 \mathrm{CAD}$ was set, while the heat transfer variables were stored every $4 \mathrm{CAD}$.

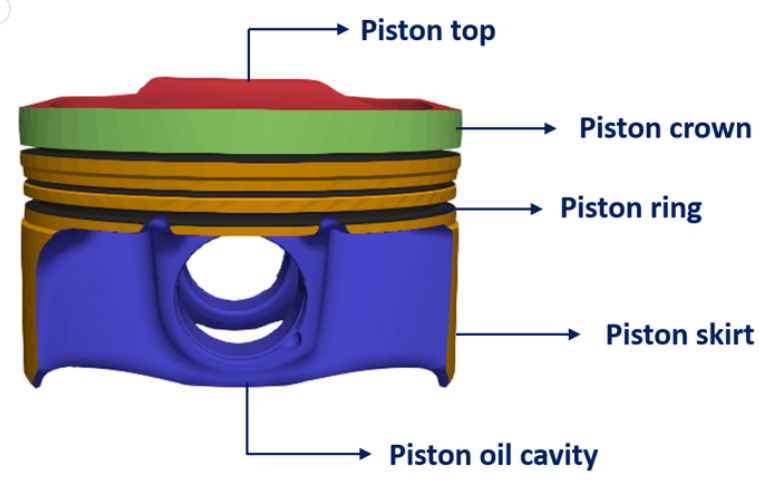

(a)

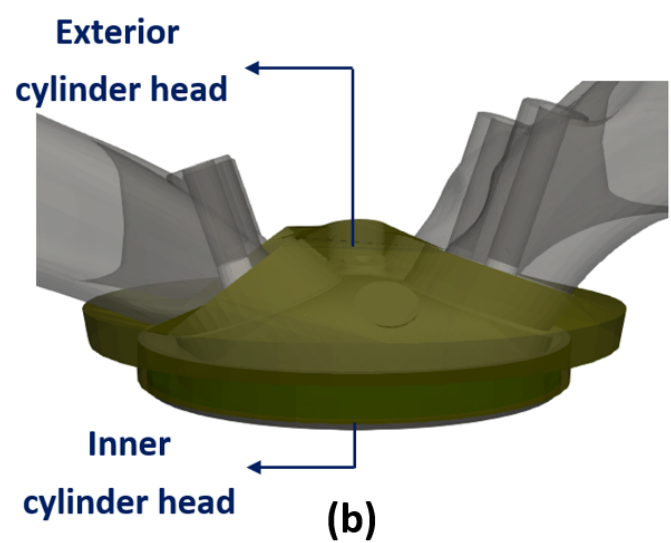

Figure 3: (a)Different zones considered for the boundary conditions on the piston and (b) on the cylinder head.

Only the temperatures of the piston and cylinder head solid surfaces were calculated with the CHT method. All other gas-exposed surfaces (liner and valves) were considered as isothermal during the whole engine cycle. The temperature boundary conditions on these walls were previously calculated by an iterative process with a lumped model [46, 47].

For the CHT simulation of the piston and cylinder head, boundary conditions have to be imposed on both sides of the fluid/solid interfaces [10, 34, 35]. The required boundary conditions for CHT at the inner solid surfaces in contact with the gas are the heat capacitance, the thermal conductivity, and the density of the wall material (aluminium or equivalent coating). The thickness of the material is directly given by the meshed geometry of the walls. It is important to set appropriate boundary conditions for the gas or fluid in contact with the walls of the piston in order to achieve the right temperature levels on the piston surface. Thus the solid piston is divided into several regions as shown in Fig. 3 to take into account the properties of the different fluids (gas, coolant) in contact with its surfaces. These are summarized in Table 3 . The boundary conditions imposed at the outer fluid interface are convection conditions, which require values for the near-wall heat transfer coefficient and near-wall gas/fluid temperature. For the piston top and crown, these parameters are directly calculated by the CFD-CHT process. For the piston ring, skirt and oil cavity values were taken from the literature.

Table 3: Boundary conditions on the piston fluid interface.

\begin{tabular}{|l|l|}
\hline Piston top & $\begin{array}{l}\text { Contact with the combustion gas } \\
\text { given by the calculation itself }\end{array}$ \\
\hline Piston crown & $\begin{array}{l}\text { Contact with combustion gas near } \\
\text { the liner wall given by the calculation }\end{array}$ \\
\hline Piston ring & Piston segments [37] \\
\hline Piston skirt & Contact with oil vapor [48] \\
\hline Piston oil cavity & Contact with cooling oil [49] \\
\hline
\end{tabular}

For the cylinder head inner wall in contact with the gas, the boundary conditions on both sides of the fluid/solid interfaces are analogous to the ones imposed on the piston. For the outer wall a convection boundary condition taking into account the heat transfer coefficient and the temperature of the cooling system is imposed, as indicated in Fig. 3 (b).

For the coated engine configuration, the coating layer is applied on the piston top surface (Fig. 3 (a)) while for the cylinder head it is applied on the inner cylinder head surface (Fig. 3 (b)), excluding the intake and exhaust valves. These are considered as isothermal for both engine configurations, with a fixed temperature calculated with the lumped model.

\section{Results and discussions}

\subsection{CFD-CHT Validation}

As explained in section 2.1, the first step in the CFDCHT calculations is to ensure adequate convergence of the cycles by comparing the pressure traces with the experimentally measured ones provided by IFPEN. This ensures that the combustion parameters have been properly set. In fact, these are tuned for the metallic engine configuration and assumed to remain unchanged for the coated configuration. In reality the coating may slightly affect the combustion process also, but the averaged pressure traces measured for both the aluminium and coated engines are practically identical, with less than 1 bar difference in peak pressure. This is seen in Fig. 4 where the corresponding curves are very similar (black for the metallic average pressure; green for the coated case). On this same figure, the measured cyclic dispersion of the SI engine is indicated by the grey shadowed area. The maximum dispersion over 300 cycles is about 25.6 bar. 
In addition, Fig. 4 shows the in-cylinder pressure traces of the last three converged cycles obtained with the CFDCHT simulations for both engine configurations: blue for the metallic configuration and red for the coated one. The maximum difference of these curves with the experimental average pressure traces (green and black) is of the order of about 10 bar. All simulated cycles fit within the experimental cyclic dispersion of both engine configurations. It may be concluded that the combustion process is adequately simulated.

When comparing the calculated pressure traces of the metallic (blue) and coated (red) engines, the maximum pressure difference is relatively small, between 2 and 5 bar. Clearly, it seems that the coating has no significant influence on the pressure traces, as is also observed experimentally.

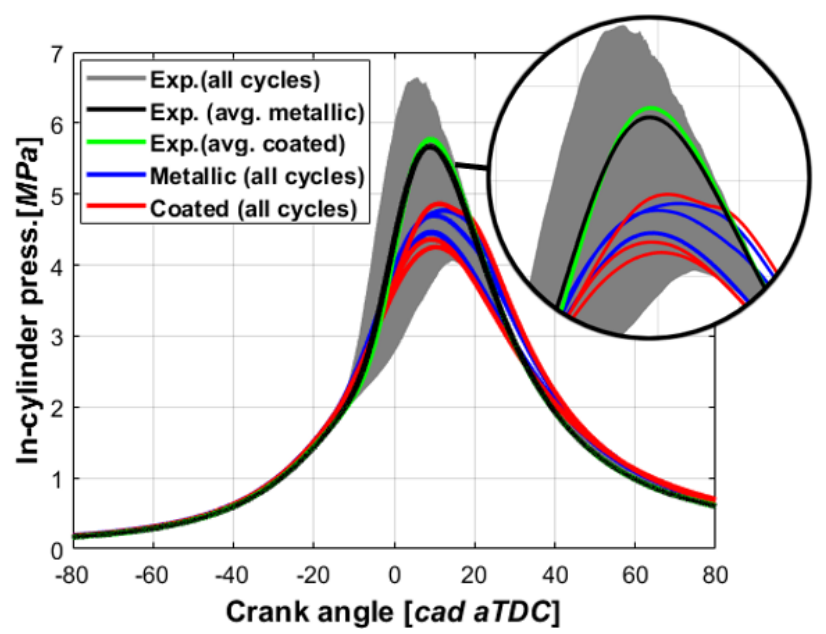

Figure 4: Calculated in-cylinder pressure traces for metallic and coated engine configurations compared to experimental measurements.

The evolution of the average wall temperatures during the engine cycle (the so-called temperature swing) is displayed in Fig. 5 (a) and Fig. 5 (b) for the CHT calculated piston and cylinder head surfaces, respectively. Note that the average is made only with the converged cycles values. In the same plot the results are also compared with the results obtained with the 1D Heat Transfer Model (HTM) 11. Though there are some differences, the CHT calculations seem to reproduce quite well the temperature swing in all configurations. As expected, the surface temperature swings on the piston and cylinder head are both significantly higher due to the application of the coating. Additional comments can be made about Fig. 5 .

$\rightarrow$ The average temperature level and evolution on the piston surface calculated with the CHT are similar to the ones predicted by the 1D HTM, although the CHT approach tends to predict higher maximum temperature in the coated configuration (about $18 \mathrm{~K}$, representing $4 \%$ in the case of the piston, less for the cylinder head).

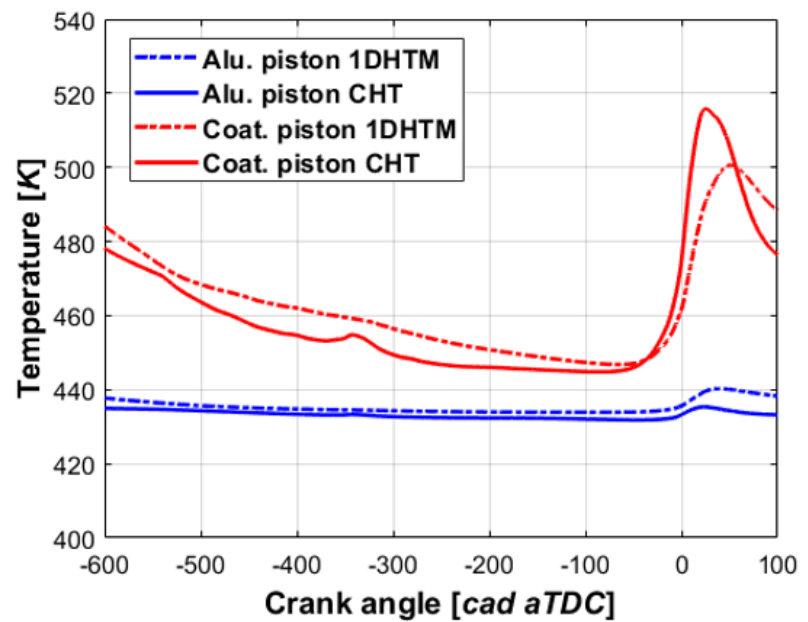

(a)

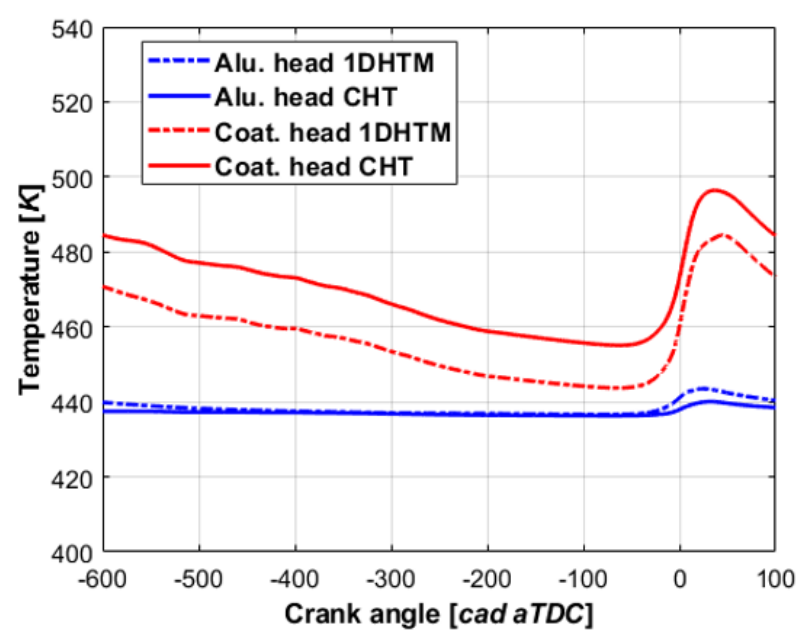

(b)

Figure 5: Temporal evolution of the average wall temperature on (a) the piston top surface and (b) the inner cylinder head surface.

$\rightarrow$ The traces for the cylinder head follow the same tendency with both models. For this surface the difference between the models is slightly larger along the cycle, by about $3 \%$.

$\rightarrow$ The temperature swing is larger on the coated piston surface than on the cylinder head surface.

$\rightarrow$ The average temperature of the coated surfaces is hotter by about 10 to $20 \mathrm{~K}$ with respect to the aluminium configuration.

The small differences observed between both models, the 1D-HTM and the CFD-CHT can be attributed to their very different assumptions: the 1D-HTM model neglects radial heat transfer, and simplifies the geometry. 


\subsection{Heat transfer analysis}

The amount of heat transferred through each of the combustion chamber walls for the metallic and coated engines are compared in Fig. 6. As shown, most of the heat is transferred through the piston and the cylinder head for both configurations. There is a reduction of $10.7 \%$ and $2.5 \%$ in the heat transferred to the coated piston and cylinder head respectively. As there is an increase of $6.4 \%$ through the liner wall, the total heat transfer through the combustion chamber walls decreases by almost $3 \%$. The fact that the largest reduction happens through the piston surface may be due to the fact that the coating layer is thicker than in the cylinder head.

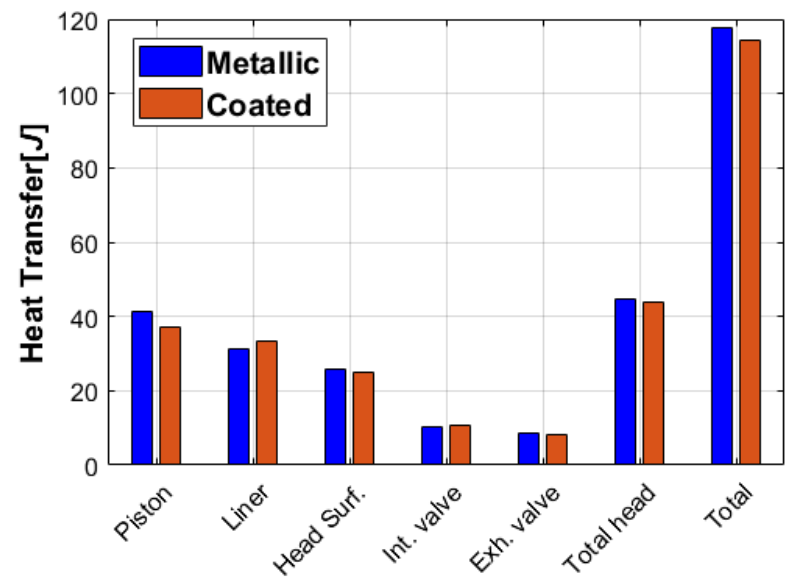

Figure 6: Heat transfer balance: comparison between metallic and coated engines.

Even so, the detailed balance of heat transfer through the coated cylinder head does not differ significantly from that of the aluminium head. $57 \%$ of the heat is transferred through the coated surface, while the rest (43\%) leaves through the valves. This is practically the same balance as for the aluminium engine ( $58 \%$ versus $42 \%$ ). The heat transfer balance is quantified in Table 4

Table 4: Heat transfer balance in the combustion chamber

\begin{tabular}{lccc}
\hline & HT Alu[J] & HT Coat[J] & Diff.[\%] \\
\hline Piston & 41.3 & 36.9 & -10.7 \\
Head Surface & 25.9 & 25.0 & -3.5 \\
Intake Valves & 10.2 & 10.5 & 2.9 \\
Exhaust Valves & 8.7 & 8.4 & -3.5 \\
Total Cyl. Head & 44.9 & 43.8 & -2.5 \\
Liner & 31.4 & 33.4 & 6.4 \\
\hline Total & 117.6 & 114.2 & -2.9 \\
\hline
\end{tabular}

The results of the CFD-CHT calculations are further analyzed in order to study the impact of coating the piston and cylinder head on the total heat transfer. The purpose is to quantify the heat loss/gain achieved when applying thermal insulation.

Fig. 7] shows the temperature spatial distribution on the solid piston at $10 \mathrm{cad}$ aTDC for the aluminium and coated configurations. Higher wall temperatures are reached for the insulated piston. For both cases the piston top is the hottest surface, as can be expected considering that this surface is directly exposed to the hot combustion gas. Also remarkable is that for the aluminium piston, the temperature gradient is mostly axial, the coolest part being naturally the piston skirt, which is in direct contact with the cooling oil. For the coated piston, there is clearly some radial temperature gradient also, meaning that some radial heat transfer takes place, which would not be taken into account by the 1D HTM model.

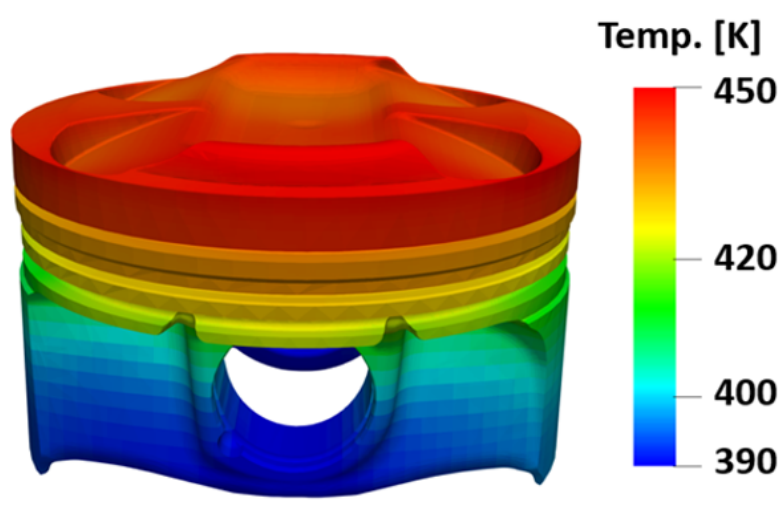

Uncoated

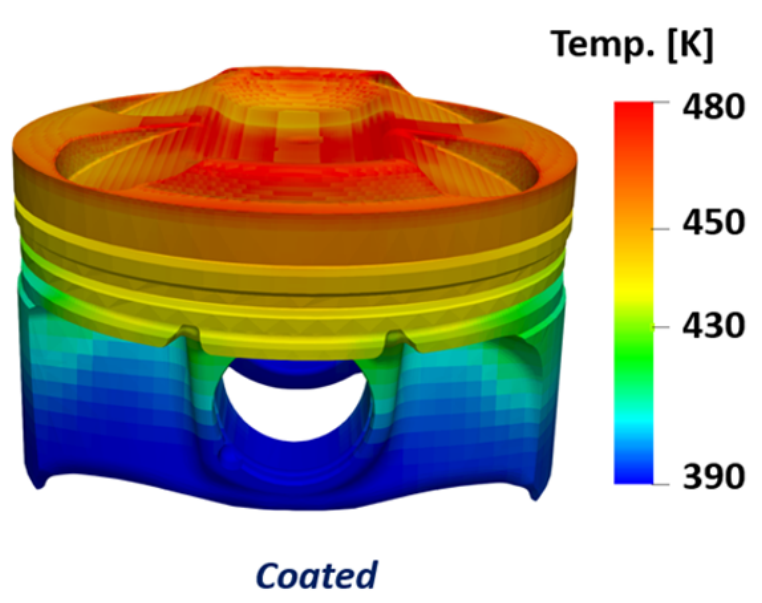

Figure 7: Wall temperature distribution in the solid piston at 10 CAD. 

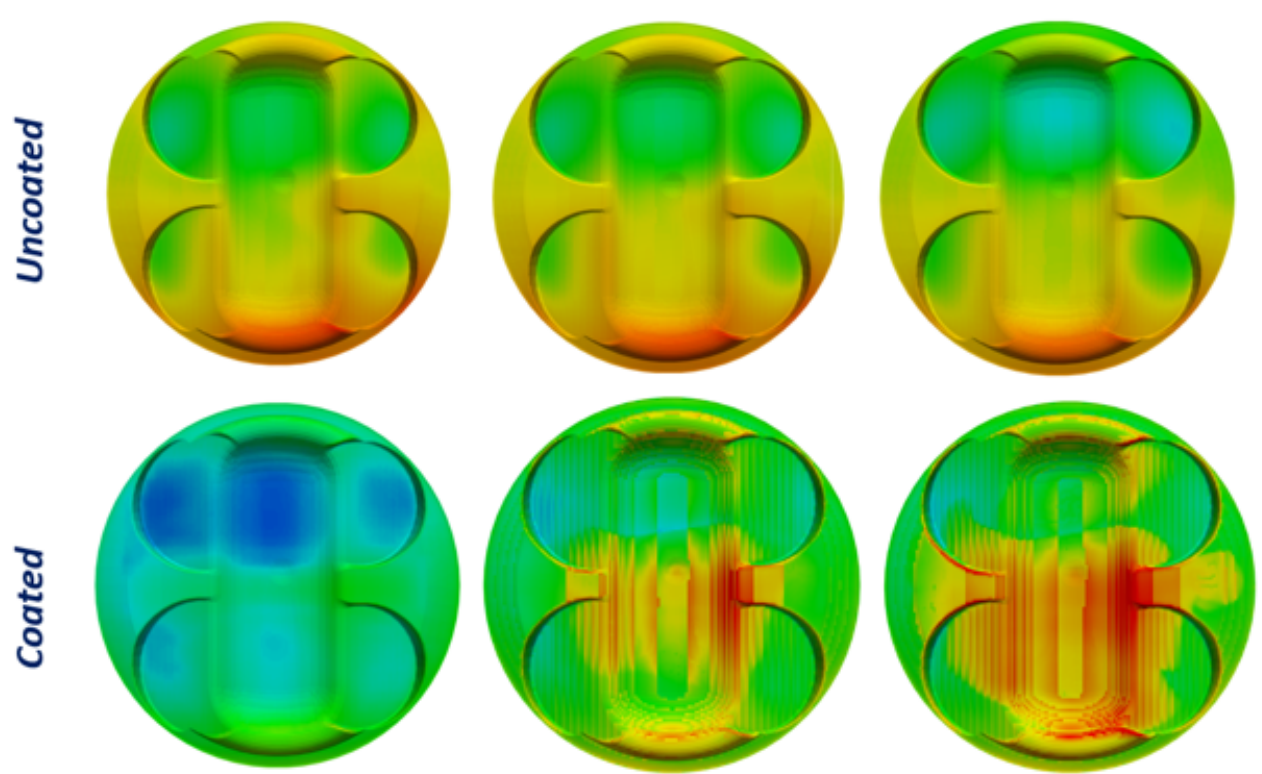

Temp. [K]

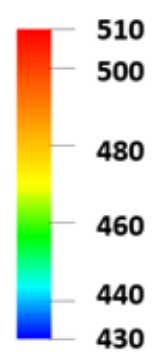

\section{CAD}

\section{Piston}
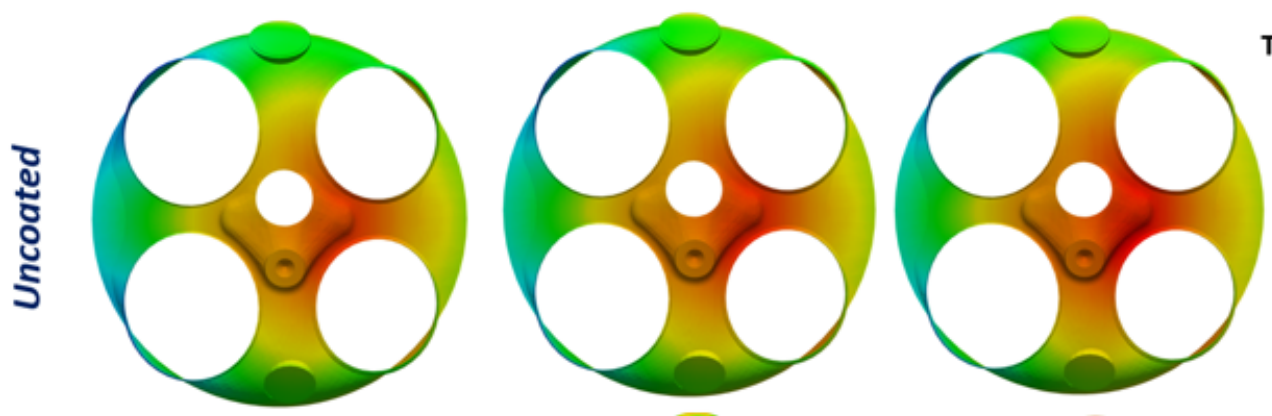

Temp. [K]
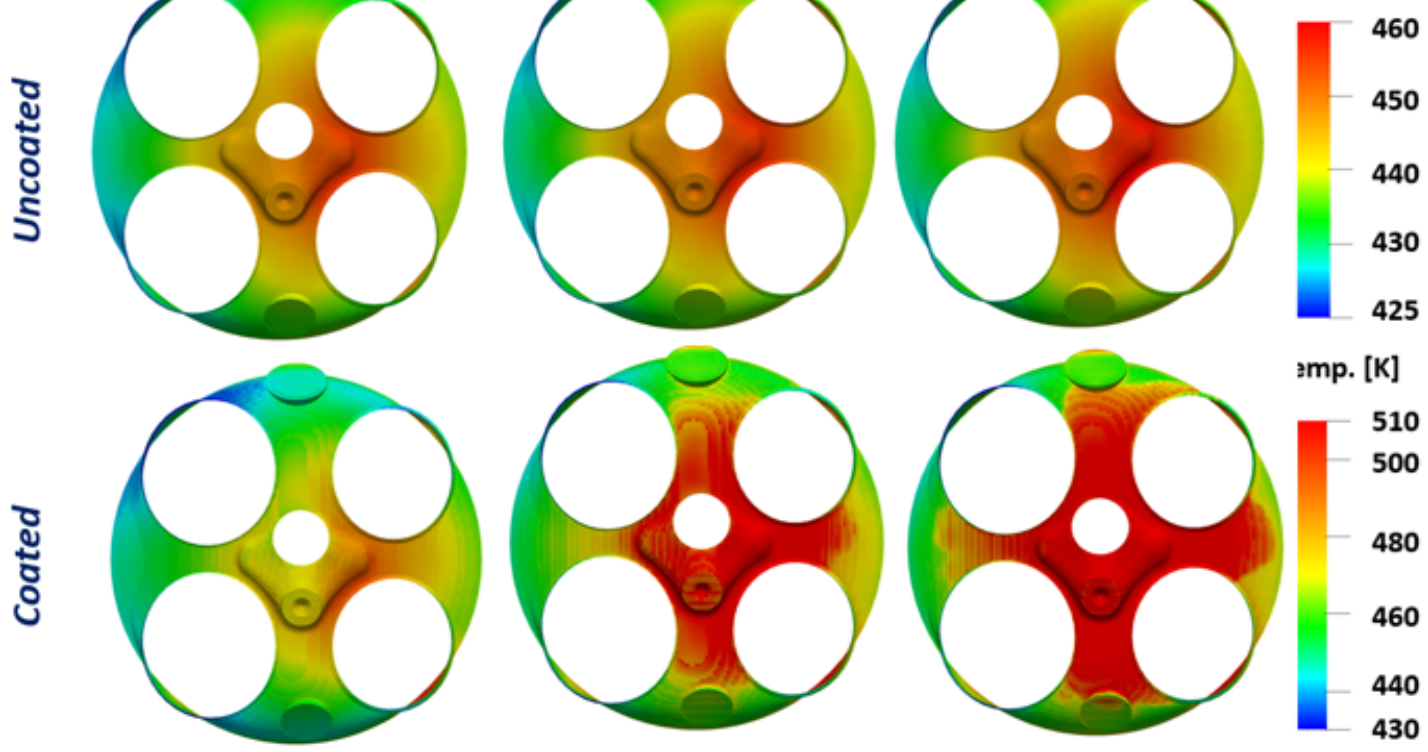

smp. [K]

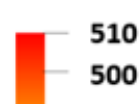

$-10 C A D$

$10 C A D$

\section{CAD}

\section{Cylinder head}

Figure 8: Temperature distribution on piston and cylinder head surfaces during combustion.

The spatial temperature distributions on the piston surface exposed to the gas for the metallic and the coated engine at three different crank angles during the combustion phase is displayed at the top of Fig. 8. For both 7 configurations, the temperature distribution is clearly nonsymmetric: the hottest area on the piston surface is located 

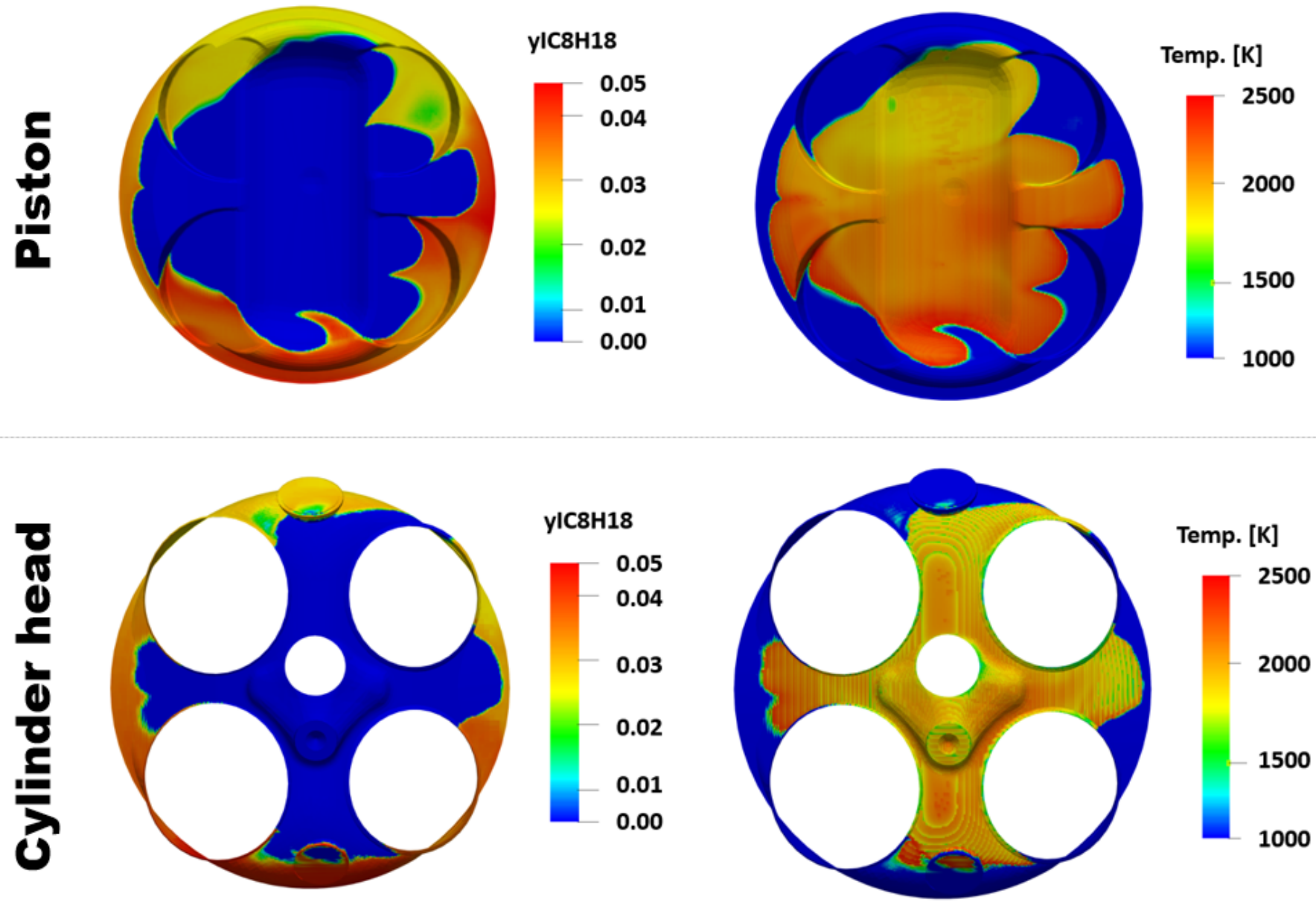

Figure 9: Burned mass fuel fraction (left) and near wall gas temperature field (right) close to piston and cylinder head for coated engine at 20 CAD.

in the lower part. The maximum thermal gradient on the aluminium piston top surface is about $20 \mathrm{~K}$ at $20 \mathrm{cad}$, while for the coated piston it is about $130 \mathrm{~K}$ at the same instant. Note that the scale does not show maximum temperature value; it has been reduced to ensure visibility of the gradient. The red colour indicates temperatures above $510 \mathrm{~K}$ and up to $570-580 \mathrm{~K}$. For the aluminium engine, there are hardly any differences between the three instants plotted, in agreement with the very low temperature swing observed in Fig. 5. The snapshot of the coated engine at 20 cad is very close to the peak temperature instant $(23,4$ cad), as is clear from the maximum temperature reached on this surface.

The bottom part of Fig. 8 shows the spatial temperature distribution on the inner surface of the cylinder head at various crank angles during combustion. The hottest spots are located at the centre of the wall for both operation conditions, while the periphery remains cooler. As expected, the maximum thermal gradient in the uncoated cylinder head is small $(35 \mathrm{~K})$ compared to that of the coated one $(80 \mathrm{~K})$. As happened also on the piston surface, the temperature distribution on the metallic cylinder head does not change much between -10 cad and $20 \mathrm{cad}$, while the warm-up is clearly visible for the coated cylinder head. Also, in the coated configuration, a clear asymmetry of the temperature distribution is visible.

Fig. 9 explains the non-uniformity of the temperature distribution on the piston and cylinder head surfaces. Indeed, it is due to the non uniform flame front propagation, as illustrated by the non-uniform gas temperature field close to the solid surfaces at 20 cad of the engine cycle (right hand side of the figure). The gas temperature follows the burned gases distribution (left hand side of figure) and shows that the combustion takes longer to extend to the periphery of both the piston and the cylinder head. In addition, the gas is also hotter on the exhaust valves side (right of cylinder head in figure). 

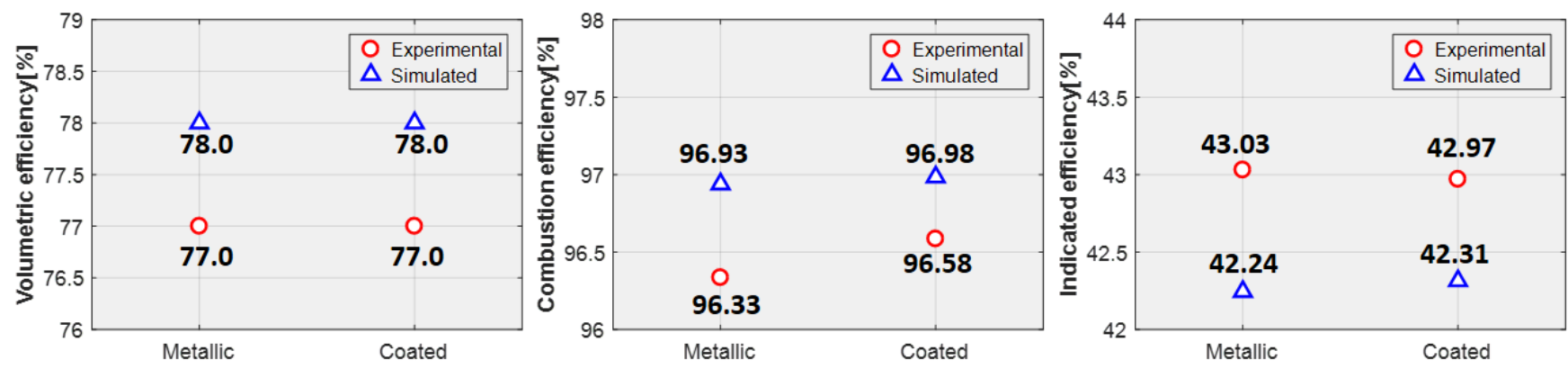

Figure 10: Comparison between the metallic and coated engines. Volumetric, combustion and indicated efficiencies .

\subsection{Engine efficiencies}

The engine volumetric, combustion and indicated efficiencies for the metallic and coated engine configurations at the studied operating condition are presented in Fig. 10 The corresponding experimental values are also plotted in these figures. As may be observed, in terms of absolute values, the numerical results are in good agreement with the experimental measurements.

Both experiments and calculations agree that there is no impact of the coating on the volumetric efficiency at this operation point. This is to be expected, because the wall temperature during the intake and exhaust phases is increased by about 20 to $40 \mathrm{~K}$ with the coating. This increase is relatively small in comparison to the average gas temperature. In addition, because of the high regime (3000 RPM), there is no time for the intake air to heat up, especially considering that it is also in contact with other cooler surfaces like the liner.

Moreover, the coating seems to provide a very low gain of $0.05 \%$ in the simulated combustion efficiency, lower than the one resulting from the measurements $(0.26 \%)$. These differences are not significant, though. The highest wall temperature swing is felt during the combustion process, but the increase is about $100 \mathrm{~K}$ versus over $2000 \mathrm{~K}$ in gas temperature during this phase. Hence, its impact on the combustion efficiency is negligible.

Finally, in the experimental test the coating seems to induce a loss of $0.14 \%$ in indicated efficiency, while the CHT results show a gain of $0.17 \%$. The problem is that the differences are so small, that they are in the range of measurements and calculation uncertainties.

Nonetheless, these results confirm that the CFD-CHT calculations are able to simulate accurately the evolution of the heat transfer through the walls of the combustion chamber during the engine cycle.

\section{Conclusions}

This work presents the methodology, validation and results of the conjugate heat transfer (CFD-CHT) simulations performed to quantify the heat losses through the walls of a single cylinder SI engine combustion chamber during the whole engine cycle, so as to assess the impact of coating the piston surface and the cylinder head on the engine efficiencies. This study has been performed with the commercial software CONVERGE.

The validation has been carried out by comparing the in-cylinder pressure with experimental measurements, and the mean wall temperature on the combustion gas exposed surface of the piston with the mean temperature obtained with a well-validated $1 \mathrm{D}$ heat transfer model. Though both models are obviously very different in nature, the CHT calculated temporal evolution of the piston and cylinder head wall temperatures follow a very similar tendency to those obtained with the 1D model. Furthermore, the average temperature level throughout the engine cycle shows maximum differences of the order of $3 \%$ in the simulations performed.

The CHT simulations have provided very useful information concerning the local heat transfer through the walls of the solid parts, as well as the temporal evolution and spatial distribution of the surfaces temperatures. In particular, they have clearly shown that there is some radial heat transfer that is never taken into account by 0D-1D models, nor in combustion CFD calculations, and this affects the surface temperature distribution. This effect is more visible for the coated engine. This in turn has an impact on the combustion process that is not seen with isothermal CFD calculations. Asymmetries have been observed in the spatial temperature, more obvious on the coated piston surface, but also on the cylinder head. These seem to be related to the non-uniform advance of the flame front, and to the presence of hotter gas in the vicinity of the exhaust pipes.

The main conclusions of this study may be summarized as follows: the coating plays its role, in the sense that the insulation ensures that the wall follows the trend of the gas temperature temporal evolution in the combustion chamber (temperature swing), which the metallic piston hardly does. This has some impact on the heat losses 
with reduction of about $3 \%$. A very slight gain of $0.17 \%$ in indicated efficiency is calculated. However, the major problem is that the calculated gain is so small, that it is in the range of measurements and calculation uncertainties.

In summary, the good agreement between the experimental measurements and the numerical solutions presented in this work confirms the reliability of the CFDCHT approach. It can be confidently used to simualte the instantaneous heat transfer during the whole engine cycle as long as the boundary conditions are properly set. This means that it is also possible to calculate with accuracy the impact of the new insulation materials on engine heat losses.

\section{Acknowledgments}

This project has received funding from the European Union's Horizon 2020 research and innovation programme under grant agreement No 724084 .

The authors wish to thank IFPEN for their permission to use their single cylinder engine geometry and experimental results, as well as Saint Gobain Research Provence for providing the coating characteristics.

The authors want to express their gratitude to CONVERGENT SCIENCE Inc. and Convergent Science GmbH for their kind support for performing the CFD-CHT calculations using CONVERGE software.

\section{References}

[1] B. Li, H. Liu, L. Yu, Z. Wang, J. Wang, Optimization of piston bowl and valve system in compression ignition engine fueled with gasoline/diesel/polyoxymethylene dimethyl ethers for high efficiency, International Journal of Engine Research (2019) 1468087419865384. doi:https://doi.org/10 $1177 / 1468087419865384$

[2] Z. Hu, J. Zhang, M. Sjöberg, W. Zeng, The use of partial fuel stratification to enable stable ultra-lean deflagration-based spark-ignition engine operation with controlled end-gas autoignition of gasoline and e85, International Journal of Engine Research (2019) 1468087419889702. doi:https://doi.org/10 $1177 / 1468087419889702$

[3] H. Yu, W. Su, Numerical study on the approach for super-high thermal efficiency in a gasoline homogeneous charge compression ignition lean-burn engine, International Journal of Engine Research (2019) 1468087419889248. doi:https://doi.org/10 $1177 / 1468087419889248$

[4] E. Gingrich, M. Tess, V. Korivi, P. Schihl, J. Saputo, G. M. Smith, S. Sampath, J. Ghandhi, The impact of piston thermal barrier coating roughness on high-load diesel operation, International Journal of Engine Research (2019) 1468087419893487. doi:https://doi.org/10.1177/1468087419893487

[5] J. Somhorst, M. Oevermann, M. Bovo, I. Denbratt, Evaluation of thermal barrier coatings and surface roughness in a singlecylinder light-duty diesel engine, International Journal of Engine Research (2019) 1468087419875837. doi:https://doi.org/10 $1177 / 1468087419875837$

[6] P. Andruskiewicz, R. Durrett, V. Gopalakrishnan, P. Najt, Dual-compression, dual-expansion piston engine assessment and optimization, International Journal of Engine Research (2019) 1468087419879609. doi:https://doi.org/10 $1177 / 1468087419879609$
[7] W. Bryzik, R. Kamo, Tacom/cummins adiabatic engine program, SAE transactions (1983) 1063-1087. doi:https://doi.org/10. $4271 / 830314$

[8] G. Woschni, W. Spindler, K. Kolesa, Heat insulation of combustion chamber walls - a measure to decrease the fuel consumption of ic engines?, SAE transactions (1987) 269-279. doi:https://doi.org/10.4271/870339

[9] D. N. Assanis, E. Badillo, Transient heat conduction in low-heatrejection engine combustion chambers, SAE transactions (1987) 82-92. doi:https://doi.org/10.4271/870156.

[10] P. Kundu, R. Scarcelli, S. Som, A. Ickes, Y. Wang, J. Kiedaisch, M. Rajkumar, Modeling heat loss through pistons and effect of thermal boundary coatings in diesel engine simulations using a conjugate heat transfer model, SAE Technical Paper (2016). doi:https://doi.org/10.4271/2016-01-2235.

[11] A. Broatch, P. Olmeda, X. Margot, J. Gómez-Soriano, Numerical simulations for evaluating the impact of advanced insulation coatings on $\mathrm{h} 2$ additivated gasoline lean combustion in a turbocharged spark-ignited engine, Applied Thermal Engineering 148 (2019) 674-683. doi:https://doi.org/10.1016/j. applthermaleng.2018.11.106

[12] V. W. Wong, W. Bauer, R. Kamo, W. Bryzik, M. Reid, Assessment of thin thermal barrier coatings for ic engines, SAE transactions (1995) 1640-1650. doi:https://doi.org/10.4271/950980

[13] A. Kikusato, K. Terahata, K. Jin, Y. Daisho, A numerical simulation study on improving the thermal efficiency of a spark ignited engine - part 2: Predicting instantaneous combustion chamber wall temperatures, heat losses and knock, SAE International Journal of Engines 7 (1) (2014) 87-95. doi:https: //doi.org/10.4271/2014-01-1066

[14] A. Taibani, M. Visaria, V. Phalke, A. Alankar, S. Krishnan, Analysis of temperature swing thermal insulation for performance improvement of diesel engines, SAE International Journal of Engines 12 (2) (2019) 117-128. doi:https://doi.org/10. 4271/03-12-02-0009

[15] S. Moser, R. O’Donnell, M. Hoffman, E. Jordan, T. Powell, Z. Filipi, Experimental investigation of low cost, low thermal conductivity thermal barrier coating on hcci combustion, efficiency, and emissions, SAE Technical Paper (2020). doi:https: //doi.org/10.4271/2020-01-1140

[16] M. Andrie, S. Kokjohn, S. Paliwal, L. S. Kamo, A. Kamo, D. Procknow, Low heat capacitance thermal barrier coatings for internal combustion engines, SAE Technical Paper (2019). doi:https://doi.org/10.4271/2019-01-0228.

[17] H. Kosaka, Y. Wakisaka, Y. Nomura, Y. Hotta, M. Koike, K. Nakakita, A. Kawaguchi, Concept of "temperature swing heat insulation" in combustion chamber walls, and appropriate thermo-physical properties for heat insulation coat, SAE International Journal of Engines 6 (1) (2013) 142-149. doi:https: //doi.org/10.4271/2013-01-0274

[18] Y. Wakisaka, M. Inayoshi, K. Fukui, H. Kosaka, Y. Hotta, A. Kawaguchi, N. Takada, Reduction of heat loss and improvement of thermal efficiency by application of "temperature swing" insulation to direct-injection diesel engines, SAE International Journal of Engines 9 (3) (2016) 1449-1459. doi:https: //doi.org/10.4271/2016-01-0661

[19] K. Fukui, Y. Wakisaka, K. Nishikawa, Y. Hattori, H. Kosaka, A. Kawaguchi, Development of instantaneous temperature measurement technique for combustion chamber surface and verification of temperature swing concept, SAE Technical Paper (2016). doi:https://doi.org/10.4271/2016-01-0675.

[20] A. Thibblin, U. Olofsson, A study of suspension plasma-sprayed insulated pistons evaluated in a heavy-duty diesel engine, International Journal of Engine Research (2019) 1468087419879530. doi:https://doi.org/10.1177/1468087419879530 
21] T. Powell, R. O'Donnell, M. Hoffman, Z. Filipi, E. H. Jordan, R. Kumar, N. J. Killingsworth, Experimental investigation of the relationship between thermal barrier coating structured porosity and homogeneous charge compression ignition engine combustion, International Journal of Engine Research (2019) 1468087419843752. doi:https://doi.org/10 $1177 / 1468087419843752$

[22] J. B. Heywood, Combustion engine fundamentals, Vol. 1st Edition, Mcgraw-Hill, Estados Unidos, 1988.

[23] C. Rakopoulos, G. Mavropoulos, D. Hountalas, Measurements and analysis of load and speed effects on the instantaneous wall heat fluxes in a direct injection air-cooled diesel engine, International Journal of Energy Research 24 (7) (2000) 587-604.

[24] J. Chang, O. Güralp, Z. Filipi, D. Assanis, T.-W. Kuo, P. Najt, R. Rask, New heat transfer correlation for an hcci engine derived from measurements of instantaneous surface heat flux, SAE transactions (2004) 1576-1593. doi:https://doi.org/10.4271/ 2004-01-2996

25] X. Dai, S. Singh, S. R. Krishnan, K. K. Srinivasan, Numerical study of combustion characteristics and emissions of a dieselmethane dual-fuel engine for a wide range of injection timings, International Journal of Engine Research 21 (5) (2020) 781-793. doi:https://doi.org/10.1177/1468087418783637

[26] J. Koch, C. Schürch, Y. M. Wright, K. Boulouchos, Reactive computational fluid dynamics modelling methane-hydrogen admixtures in internal combustion engines part ii: Large eddy simulation, International Journal of Engine Research (2020) 1468087420910348. doi:https://doi.org/10.1177/ 1468087420910348

[27] M. M. Patil, A. Pise, N. Gokhale, Simulation of conjugate heat transfer (cht) between engine head and cooling medium of diesel engine, SAE Technical Paper (2015). doi:https://doi.org/10 4271/2015-01-1662.

[28] A. Broatch, P. Olmeda, A. García, J. Salvador-Iborra, A. Warey, Impact of swirl on in-cylinder heat transfer in a light-duty diesel engine, Energy 119 (2017) 1010-1023. doi:https://doi.org/ 10.1016/j.energy.2016.11.040

[29] P. Andruskiewicz, P. Najt, R. Durrett, S. Biesboer, T. Schaedler, R. Payri, Analysis of the effects of wall temperature swing on reciprocating internal combustion engine processes, International Journal of Engine Research 19 (4) (2018) 461-473. doi:https: //doi.org/10.1177/1468087417717903.

[30] A. Poubeau, A. Vauvy, F. Duffour, J.-M. Zaccardi, G. d. Paola, M. Abramczuk, Modeling investigation of thermal insulation approaches for low heat rejection diesel engines using a conjugate heat transfer model, International Journal of Engine Research 20 (1) (2019) 92-104. doi:https://doi.org/10.1177/ 1468087418818264

[31] H. Li, C. J. Rutland, F. E. Hernández Pérez, H. G. Im, Large-eddy spray simulation under direct-injection sparkignition engine-like conditions with an integrated atomization/breakup model, International Journal of Engine Research (2020) 1468087419881867. doi:https://doi.org/10 $1177 / 1468087419881867$

[32] F. Rulli, A. Barbato, S. Fontanesi, A. d'Adamo, Large eddy simulation analysis of the turbulent flow in an optically accessible internal combustion engine using the overset mesh technique, International Journal of Engine Research (2020) 1468087419896469. doi:https://doi.org/10.1177/1468087419896469

[33] A. Broatch, P. Olmeda, X. Margot, J. Gomez-Soriano, A onedimensional modeling study on the effect of advanced insulation coatings on internal combustion engine efficiency, International Journal of Engine Research (2020) 1468087420921584. doi: https://doi.org/10.1177/1468087420921584

[34] A. Broatch, X. Margot, J. Garcia-Tiscar, J. Escalona, Validation and analysis of heat losses prediction using conjugate heat transfer simulation for an internal combustion engine, SAE Technical Paper (2019). doi:https://doi.org/10.4271/2019-24-0091
[35] A. Broatch, P. Olmeda, X. Margot, J. Escalona, New approach to study the heat transfer in internal combustion engines by $3 \mathrm{~d}$ modelling, International Journal of Thermal Sciences 138 (2019) 405415. doi:https://doi.org/10.1016/j.ijthermalsci.2019.01 006

[36] J. Chérel, J.-M. Zaccardi, B. Bouteiller, A. Allimant, Experimental assessment of new insulation coatings for lean burn spark-ignited engines, Oil \& Gas Science and Technology-Revue d'IFP Energies nouvelles 75 (2020) 11. doi:https://doi.org/ $10.2516 /$ ogst/2020006

[37] Convergent science inc., CONVERGE 2.3 Theory Manual (2018).

[38] A. Broatch, X. Margot, R. Novella, J. Gómez-Soriano, Combustion noise analysis of partially premixed combustion concept using gasoline fuel in a 2-stroke engine, Energy 107 (2016) 612624. doi:https://doi.org/10.1016/j.energy.2016.04.045

[39] A. Broatch, X. Margot, R. Novella, J. Gomez-Soriano, Impact of the injector design on the combustion noise of gasoline partially premixed combustion in a 2-stroke engine, Applied Thermal Engineering 119 (2017) 530-540. doi:https: //doi.org/10.1016/j.applthermaleng.2017.03.081

[40] P. Senecal, E. Pomraning, K. Richards, T. Briggs, C. Choi, R. McDavid, M. Patterson, Multi-dimensional modeling of directinjection diesel spray liquid length and flame lift-off length using cfd and parallel detailed chemistry, SAE transactions (2003) 1331-1351. doi:https://doi.org/10.4271/2003-01-1043

[41] V. Yakhot, S. A. Orszag, Renormalization group analysis of turbulence. i. basic theory, Journal of scientific computing 1 (1) (1986) 3-51. doi:https://doi.org/10.1007/BF01061452

[42] P. O'rourke, A. Amsden, A particle numerical model for wall film dynamics in port-injected engines, SAE transactions (1996) 2000-2013. doi:https://doi.org/10.4271/961961.

[43] L. Anthony Amsden, A block-structured kiva program for engines with vertical or canted valves, Los Alamos National Laboratory (1999)

[44] O. Redlich, J. N. Kwong, On the thermodynamics of solutions. v. an equation of state. fugacities of gaseous solutions., Chemical reviews 44 (1) (1949) 233-244.

[45] R. I. Issa, Solution of the implicitly discretised fluid flow equations by operator-splitting, Journal of computational physics 62 (1) (1986) 40-65. doi:https://doi.org/10.1016/ 0021-9991(86) 90099-9.

[46] A. Torregrosa, P. Olmeda, B. Degraeuwe, M. Reyes, A concise wall temperature model for di diesel engines, Applied Thermal Engineering 26 (11-12) (2006) 1320-1327. doi:https://doi org/10.1016/j.applthermaleng.2005.10.021

[47] A. J. Torregrosa, P. Olmeda, J. Martín, C. Romero, A tool for predicting the thermal performance of a diesel engine, Heat transfer engineering 32 (10) (2011) 891-904. doi:https://doi org/10.1080/01457632.2011.548639

[48] L. Jarrier, J. Champoussin, R. Yu, D. Gentile, Warm-up of a di diesel engine: experiment and modeling, SAE Technical Paper (2000). doi:https://doi.org/10.4271/2000-01-0299

[49] Y. Lu, X. Zhang, P. Xiang, D. Dong, Analysis of thermal temperature fields and thermal stress under steady temperature field of diesel engine piston, Applied thermal engineering 113 (2017) 796812. doi:https://doi.org/10.1016/j.applthermaleng. 2016 11.070 